\title{
IMPLEMENTASI MODULE GOOGLE PAGESPEED PADA APACHE WEB SERVER UNTUK MENINGKATKAN PERFORMA APLIKASI WEB
}

\author{
Muhammad Faizal Kurniawan ${ }^{1)}$, Wahyu Setianto ${ }^{2)}$, Agus Ilyas ${ }^{3)}$ \\ STMIK Widya Pratama J1. Patriot No. 25 Pekalongan \\ faizal@stmik-wp.ac.id, kian@stmik-wp.ac.id, agusilyas@stmik-wp.ac.id
}

\begin{abstract}
Abstrak
Performa aplikasi web salah satunya dapat dipengaruhi dari konfigurasi web server yang tepat. Meskipun memiliki hardware dengan spesfikasi yang tinggi namun jika konfigurasinya tidak tepat maka performa aplikasi web yang ada di dalam web server tersebut tidak akan meningkat. Salah satu cara agar aplikasi web dapat diakses dengan cepat adalah dengan mengecilkan ukuran file yang di unduh dari web server ke browser pengguna. Selama ini developer web akan melakukan kompresi terhadap file-file gambar, js dan css sebelum diupload ke web server. Google Page Speed dalah sebuah modul ekternal yang dapat dikonfigurasikan ke dalam Apache web server untuk menggantikan tugas developer web dalam mengkompresi file-file sebelum diunggah. Fungsi dari modul ini ini adalah secara otomatis akan melakukan kompresi terhadap file-file gambar, css dan js secara realtime. Penelitian ini bertujuan untuk menguji performa aplikasi web sebelum dan setelah mengimplementasikan module Google Page Speed pada web server yang dalam penelitian ini menggunakan Apache Web Server.
\end{abstract}

Kata kunci: optimasi web, kompresi konten, web server

\section{Pendahuluan}

Seiring dengan meningkatnya layanan akses ke jaringan internet, maka semakin banyak aplikasiaplikasi berbasis web yang dibuat. Aplikasi berbasis web memiliki kelebihan dibandingkan dengan aplikasi desktop antara lain karena tidak perlu diinstall di perangkat pengguna dan proses update dapat perlu dilakukan. Portal berita, media sosial, game, aplikasi perkantoran hingga ecommerce sebagian besar tersedia dalam bentuk aplikasi web. Berbeda dengan aplikasi desktop yang terinstall langsung pada perangkat pengguna, aplikasi web disimpan didalam web server. Web server bertugas menjembatani kebutuhan pengguna dan aplikasi. Salah satu web server yang banyak digunakan adalah Apache.

Apache banyak digunakan karena kemudahan instalasi dan konfigurasinya. Seluruh file pada aplikasi web tersimpan di dalam web server dan pengguna aplikasi dapat mengakses melalui jaringan baik itu intranet maupun internet. Karena file-file pada aplikasi web tersimpan di dalam web server, maka cepat atau tidaknya loading sebuah aplikasi web dapat dipengaruhi oleh beberapa hal antara lain: bandwith jaringan yang tersedia, spesifikasi dan konfigurasi web server dan perfoma dari aplikasi web itu sendiri.
Berbagai penelitian telah dilakukan untuk meningkatkan performa aplikasi web baik dari sisi jaringan, web server maupun teknik pemrogramannya. Salah satu cara meningkatkan kecepatan aplikasi web adalah dengan cara mengusahakan agar file-file assets (file gambar, css dan js) yang diakses oleh pengguna berukuran sekecil mungkin, karena semakin kecil filenya maka makin kecil bandwith yang dibutuhkan untuk mengaksesnya dan makin cepat pula loading aplikasinya. File-file dapat dikecilkan dengan cara melakukan kompresi sebelum diunggah di webserver, namun demikian cara ini tentunya memakan waktu dan tenaga bagi pada developer web.

Modul google page speed adalah sebuah module tambahan yang dapat diinstall pada web server. Saat ini modul page speed tersedia untuk Apache dan Nginx. Modul ini berfungsi untuk mengotomatisasi proses kompresi file assets. Modul page speed secara otomatis membuat potongan gambar sesuai dengan ukuran yang didefinisikan. Module page speed juga mampu melakukan kompresi dan caching terdapat file css dan js secara otomatis. Penelitian ini bertujuan mengimplementasikan modul google page speed pada Apache web server dan untuk menguji 
performa aplikasi web sebelum dan setelah web server dikonfigurasi dengan modul ini.

Hipotesa dari penelitian ini adalah performa aplikasi web akan meningkat setelah google page speed diaktifkan. Namun kemungkinan peningkatan performa akan terjadi setelah web diakses pada kali kedua, sedangkan pada saat pertama diakses kemungkinan akan terjadi perlambatan karena ada proses kompresi dan caching yang dilakukan oleh module page speed. Proses pengujian akan dilakukan menggunakan metode pretest-postest dengan tool penggujian yaitu: GTMetrix dan Google PageSpeed Insight.

\section{Metode Penelitian}

\subsection{Kerangka Pemikiran}

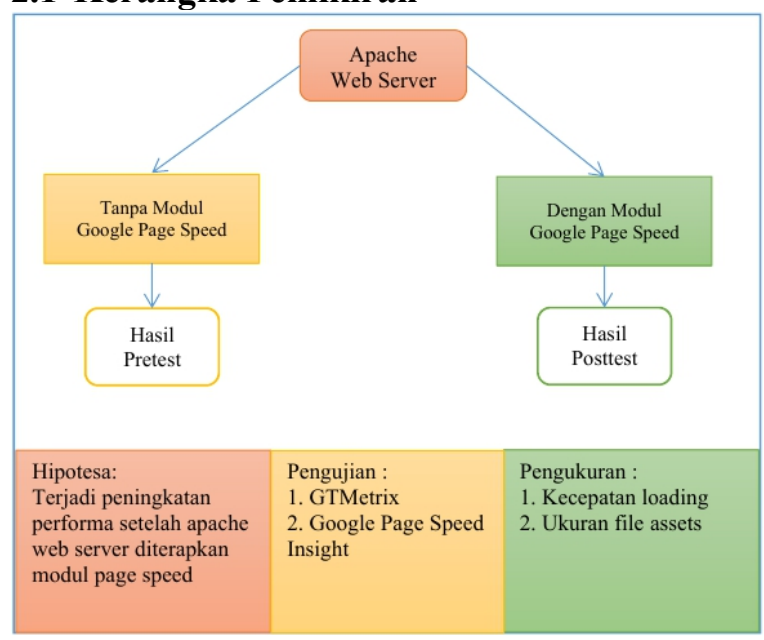

Gambar 1. Kerangka Pemikiran

\subsection{Tahapan Eksperimen}

Beberapa tahapan dilakukan dilakukan melakukan eksperimen, yaitu: (1) Persiapan (2) Instalasi dan Konfigurasi VPS (3) Pembuatan Halaman Uji (4) Pengujian

\subsubsection{Persiapan}

Pada tahap persiapan, dilakukan dengan mempersiapkan lingkungan server. Server yang digunakan memiliki spesifikasi sebagai berikut:

- CPU 1 Core

- Memory 1024 MB

- SSD 20 GB

- OS : Debian 10

\subsubsection{Instalasi dan konfigurasi VPS}

Tahapan berikutnya adalah dengan melakukan instalasi dan konfigurasi VPS. Tahapan instalasi adalah:

Instalasi Apache 2.4, perintah untuk melakukan instalasi Apache 2.4 adalah sebagai berikut:

sudo apt-get install apache2

Instalasi Module PageSpeed, modul pagespeed dapat diunduh dilaman resmi Google Developer, yaitu dialamat url berikut: https://developers.google.com/speed/pagespeed/ module. Perintah yang digunakan untuk melakukan tahapan instalasi modul pagespeed adalah

wget

https://dlssl.google.com/dl/linux/direct/mod-pagespeedstable_current_amd64.deb dgpk -i mod-pagespeedstable_current_amd64.deb

\subsubsection{Pembuatan Halaman Uji}

Langkah berikutnya adalah dengan membuat halaman web sebagai bahan uji coba. Halaman yang dibuat memuat assets berupa gambar, css dan javascript.

\subsubsection{Pengujian}

Tahap terakhir adalah dengan melakukan pengujian pre test dan post test. Alat bantu pengujian menggunakan GTMetrix dan Google PageSpeed Insight, dimana akan dibanding performa halaman yang telah dibuat sebelumnya pada saat sebelum mengaktifkan modul pagespeed dan sesudah mengaktifkan modul pagespeed.

\section{Hasil Sistem}

Halaman uji coba yang dibuat pada penelitian ini adalah sebuah halaman web yang dibuat dengan format HTML yang memuat:

- Gambar yang berukuran antara $244 \mathrm{~KB}$ hingga $2 \mathrm{MB}$

- Non-compressed file css yang merupakan file bawaan dari Bootstrap dan juga menggunakan tema dari Bootwatch.

- Non-compressed file javascript yang merupakan file bawaan Boostrap dan juga tambahan JQuery. 


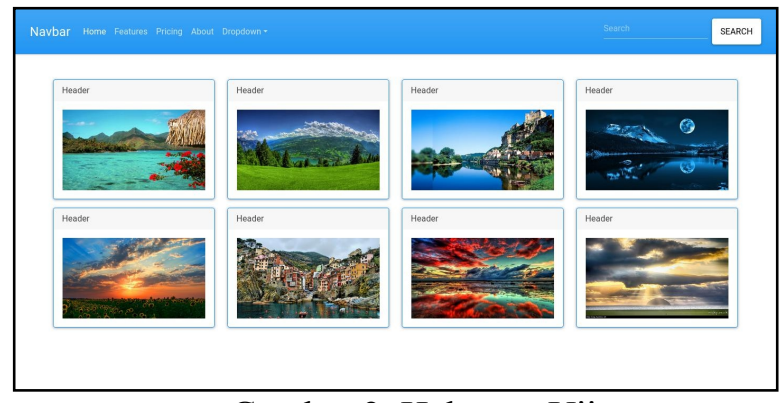

Gambar 2. Halaman Uji

\section{Pengujian}

\subsection{Uji Pre Test}

Uji pre test dilakukan dengan mengukur halaman uji coba pada Apache 2.4 sebelum mengaktifkan modul PageSpeed. Berikut ini adalah hasil tangkapan layar dari GTmetrix dan Google PageSpeed Insight.

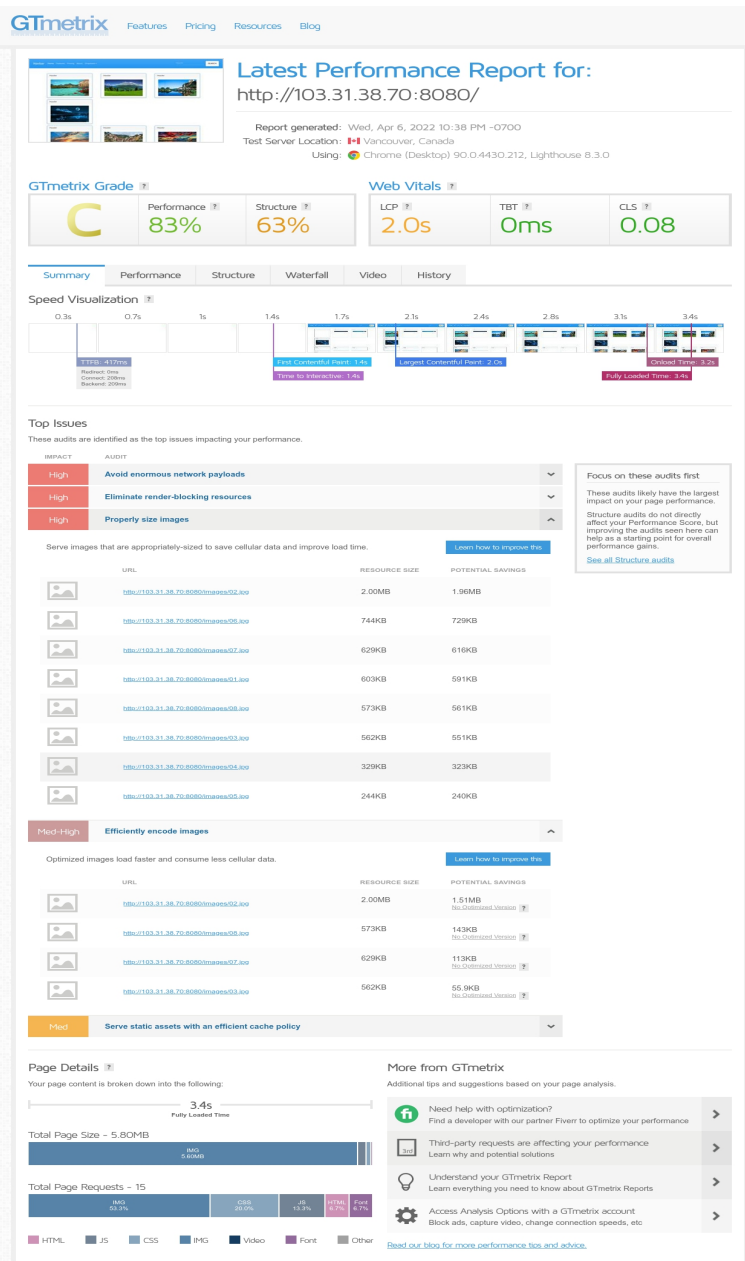

Gambar 3. Hasil Pre Test dengan GTmetrix

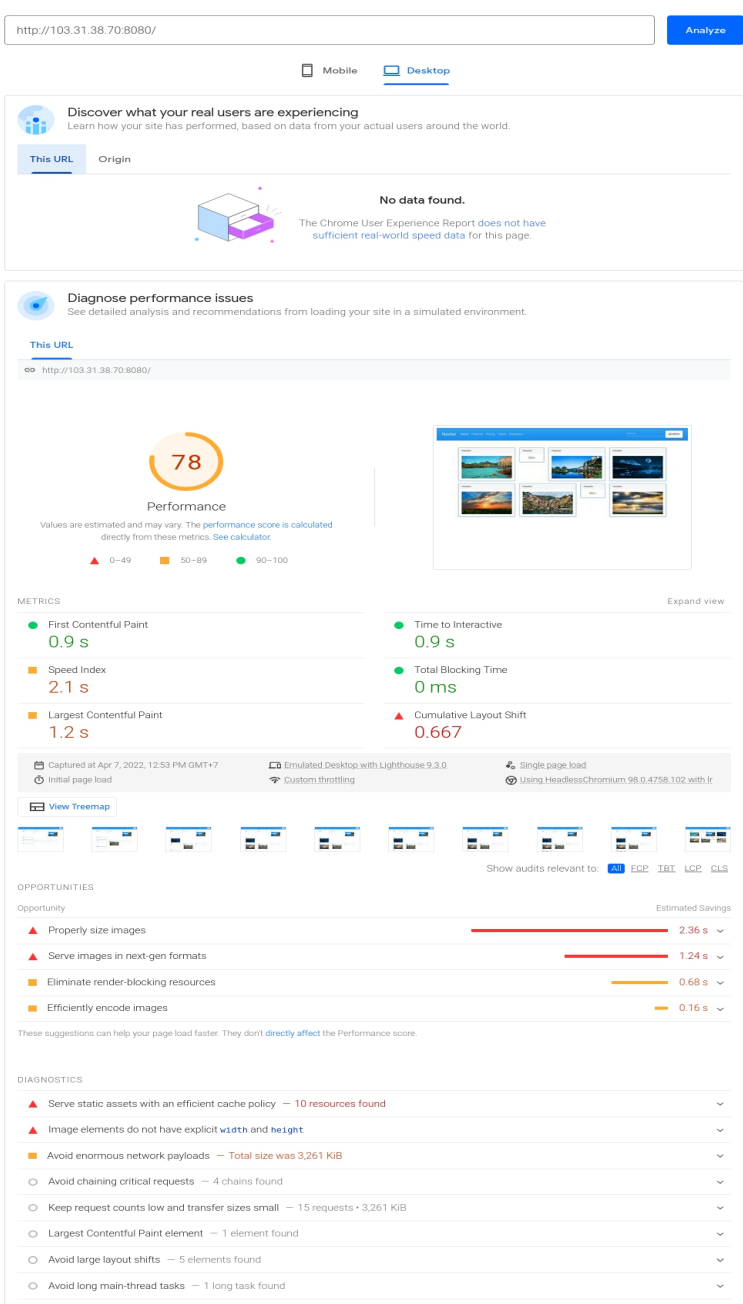

Gambar 4. Hasil Pre Test dengan Google PageSpeed Insight

Melihat hasil pre test dari kedua tools (GTmetrix dan Google PageSpeed Insight), terlihat ada salah 1 indikator yang direkomendasikan oleh kedunya yang berkaitan dengan penelitian ini yaitu properly size images. Hal disebabkan karena website uji coba menggunakan gambar dengan ukuran 1920x1080 tetapi hanya menampilkannya dengan ukuran lebar 270. Hal ini tentunya akan membuat loading halaman akan lambat, karena file gambar yang diunduh oleh browser tetap file gambar yang berukuran 1090x080. Idealnya jika jika gambar yang akan ditampilkan berukuran lebar 270 maka seharusnya gambar harus terlebih dulu di resize dengan ukurun lebar 270 juga. Harapannya dengan menggunakan modul PageSpeed gambar-gambar akan diresize terlebih secara 


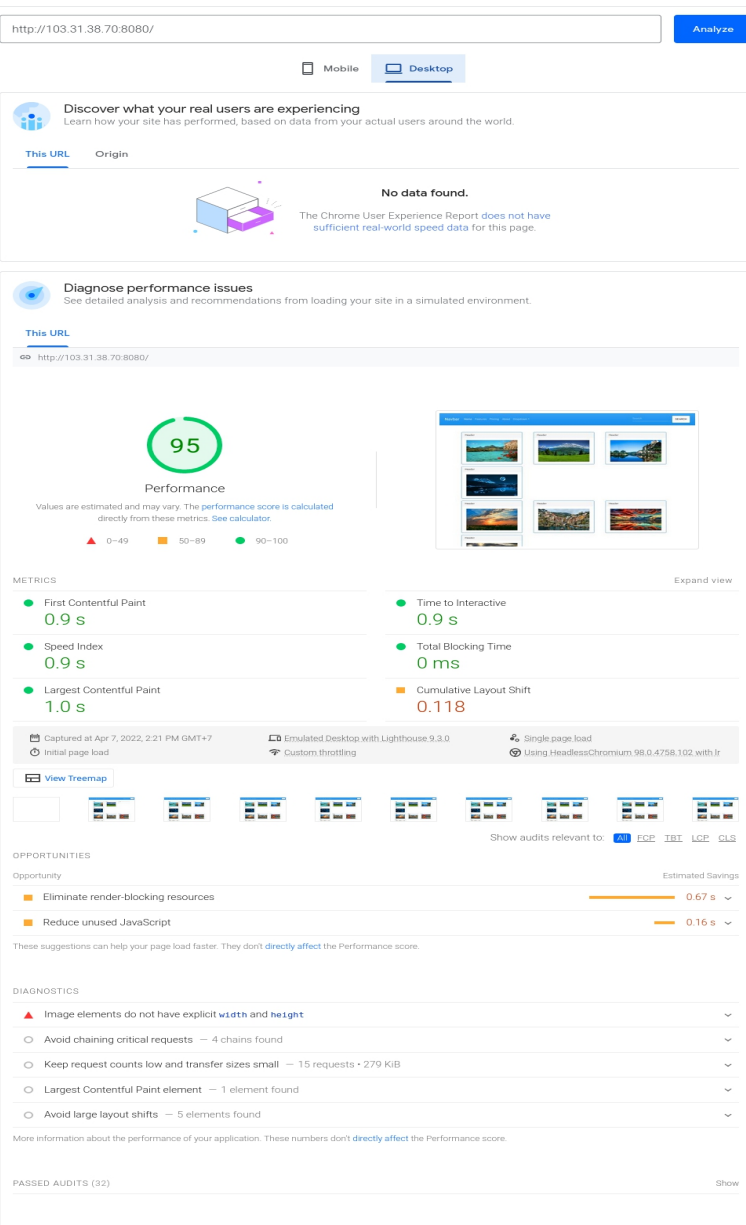

Gambar 10. Hasil pengujian Google PageSpeed Insight setelah mengaktifkan modul PageSpeed

\section{Kesimpulan dan Saran}

\subsection{Kesimpulan}

Dari hasil penelitian yang telah dilakukan terdapat beberapa hal yang menjadi kesimpulan antara lain:

(1) Modul PageSpeed dapat diterapkan dengan mudah dengan menggunakan Apache web server. (2) Modul PageSpeed terbukti dapat mengoptimalkan file-file assets pada halaman web.

(3) Hasil pengujian menggunakan GTmetrix dan Google PageSpeed Insight menunjukkan bahwa setelah menerapkan module PageSpeed perfoma halaman web uji coba menjadi meningkat dan sangat baik.

\subsection{Saran}

Penerapan modul PageSpeed pada Apache web server telah terbukti meningkatkan perfoma halaman web. Namun demikian penelitian hanya terbatas membahas penggunaan modul tersebut pada Apache web server. Saran untuk peneliti selanjutnya adalah dengan menerapkan modul ini untuk web server lain seperti Nginx, Open Lite Speed dan lain sebagainya.

\section{DAFTAR PUSTAKA}

Garry. (2012). Apa Kegunaan Folder Assets dalam Yii Framework? Retrieved September 28, 2021, from http://www.computesta.com/blog/2012/03/ apa- kegunaan-folder-assets-dalam-yiiframework/\#.YVXfLbxBzeM

Nurmiati, E. (2012). Analisis dan Perancangan Web Server Pada Handphone. Studia Informatika: Jurnal Sistem Informasi, 5(2), 1-17. Retrieved from http://download.portalgaruda.org/article.ph p? article $=2481 \&$ val $=329 \&$ title $=A$

NALISIS DAN PERANCANGAN WEB SERVER PADA HANDPHONE

Dewanto, I. Joko. (2006). Web Desain (Metode Aplikasi dan Implementasi). Yogyakarta: Graha Ilmu.

Saraswati, I., Praptodiyono, S., Pramudyo, A. S., \& Kurniawan. (2019). Increasing web server performance using the web balancing method. IOP Conference Series: Materials Science and Engineering, 673(1). https://doi.org/10.1088/1757899X/673/1/012065

N. Suradkar and S. Lomte, "VMware ESXi: Virtual Web Server performance evaluation with weighttp Benchmark," 2020 IEEE International Conference on Advent Trends in Multidisciplinary Research and Innovation (ICATMRI), 2020, pp. 1-4, doi: 10.1109/ICATMRI51801.2020.9398491.

Google. (2018). PageSpeed Modules. https://developers.google.com/speed/pages peed/module 